DOI: 10.20472/TEC.2019.008.011

\author{
MARK KAAHWA \\ Vrije universiteit Brussels, Att: Mark Kaahwa, Belgium
}

CHANG ZHU

Vrije universiteit Brussels, Belgium

MOSES MUHUMUZA

Mountains of the Moon University, Uganda

RODGERS MUTYEBERE

Mountains of the Moon University, Uganda

ROBERT MAWENU

Mountains of the Moon University, Uganda

\title{
ASSESSING THE EFFICACY OF AUDIO MEDIA TECHNOLOGY IN ENHANCING FINANCIAL LITERACY KNOWLEDGE OF RADIO LISTENING CLUB MEMBERS. A CASE OF SELECTED RURAL COMMUNITIES IN WESTERN UGANDA
}

\begin{abstract}
:
The principal aim of this study was to assess the efficacy of audio media technology (AMT) in the form of radio broadcasts and audio CDs in equipping Radio Listening Club Members (RLCMs) with financial literacy knowledge (FLK). Although audio media technology is acknowledged as the most important medium for communicating with rural populations, it is not known whether it can assist RLCMs to increase their FLK. A total of 939 participants from Rwenzori region in western Uganda participated in this study which involved a pre-test, an intervention, and a post-test experience. Pre-test analysis identified two cohorts, one cohort consisted of 157 members who were found with relevant knowledge of financial literacy and the other cohort consisted of 782 members who were found with low levels of knowledge even on the most basic aspects of financial literacy. The first cohort was excluded from the study as this research could not add much to their knowledge. Data was collected using a structured questionnaire before and after AMT intervention. We analysed the knowledge levels of respondents before and after in the following financial literacy themes; personal financial management, saving management, loan acquisition and management, investment management and financial service providers and making payments. Results showed that the use of AMT in financial literacy has a positive causal impact. For most of the items under these scales, they showed an increase in means after respondents received the AMT intervention. An indication that although they had poor initial knowledge on most financial literacy aspects, their knowledge significantly changed after attending the AMT training. Results further revealed that the listenership at the RLCs and listenership at individual level showed a statistically significant difference only in three areas; savings, investment, and personal financial management. Members who listened from the RLCs appeared to have more knowledge in financial literacy on savings, investment, and personal financial management, unlike their counterparts who listened individually. Moreover, apart from age other demographic characteristics such as gender and level of education did not correlate with knowledge uptake regarding financial literacy. Based on these findings thus, we conclude that
\end{abstract}


well designed AMT in the form of radio broadcasts and audio CDs is an effective and cost-effective mechanism through which knowledge levels of community people regarding financial literacy can be enhanced.

\section{Keywords:}

Financial literacy, Radio Listening clubs, audio media technology, information tool, rural communities.

JEL Classification: 129 


\subsection{Introduction}

One life skill that is rarely attended to in both formal and informal education is the aspect of financial literacy, yet it appears that majority of the population in most countries possess very basic financial knowledge with very limited understanding of the obvious financial concepts such as making budgets, planning for expenditure, savings, loans management, etc. (Schwella \& Nieuwenhuyzen, 2014). Besides, Schwella and Nieuwenhuyzen indicate that such and many more financial literacy aspects are lacking amongst sizeable proportions of the population in every country surveyed. Furthermore, the study revealed that some respondents, were overconfident, even when they gave wrong answers to the survey, they could not admit that they were wrong. Low financial literacy levels were even observed even in some of the developed economies, for example, one research found that several studies and surveys reveal that the knowledge levels of the population in the United States as regards financial literacy are lower than expected (Lusardi and Mitchelli, 2007; Lusard \& Mitchell, 2009). This is congruent with another study that found several studies focusing on the U.S. population or specific subgroups of the population have constantly documented very low levels of financial literacy (Lusardi, 2008). Similar findings are reported by Hilgert, Hogarth and Beverly (2003) who evaluated data of 1000 respondents aged between 18 to 98 years. Respondents were issued a 28-item questionnaire containing true/false financial literacy quiz, covering basic knowledge on credit facilities, savings management, mortgages, and general personal financial management and results indicate that most respondents performed below average indicating widespread financial illiteracy among the whole population. In their study conducted in Uganda Mundy and Masok (2011) indicate that financial literacy education should be a continuous training programme because their findings revealed that even individuals with good financial skills find some aspects of financial literacy challenging. People often find money issues worrying, tasking and confusing. In addition, some people in Uganda, especially those in the rural communities have not received financial education throughout their life and do not know how to access information and support which could help them to manage their money well. Financial literacy educational initiatives are thus desired to address the need for financial literacy and therefore, enhance the financial well-being of members of society. One of the reasons why individuals are not making appropriate financial decisions is perhaps because they lack knowledge on financial literacy and thus well-prepared financial literacy education programmes would be very helpful in that endeavour. Financial literacy trainings should be geared towards improving the skills, knowledge, and financial behaviour of individuals which translates into improved investment ventures, savings and descent quality of living (Vitt et al., 2005). An author in one study observed that financial literacy includes but is not limited to: read, scrutinise, manage and write about the personal and family financial obligations that affect material well-being. It includes the ability to make correct financial choices, discuss money and other financial related issues with clarity and precision. It means being able to respond competently to life events that affect every day financial decisions, including those in the general economy of the country (Sweta and 2014 cited in Vitt et al., 2000).

One study by Atkinson and Messy (2011) observes that across the globe financial literacy is today more than ever before being documented as one of the core skills, very vital for everyone operating in an increasingly intricate financial landscape. Therefore, private and public institutions around the world are doing all that is possible to improve the level of financial literacy amongst the population. Some countries have embarked on a national plan of putting in place financial 
education to provide learning opportunities throughout the entire person's life. Furthermore, in a related study, it is observed that many countries around the world face acute and widespread deficiencies concerning financial literacy and this has prompted the launch of financial literacy programmes in many sectors of those countries (Atkinson \& Messy, 2011). Some countries are already making observable progress in that line.

However, Lusardi (2008) observes that low literacy levels and lack of proper channels of information are already stifling these efforts because ignorance of basic financial literacy knowledge for rural communities can directly be linked to lack of information. Although there is a desire to circulate information including financial literacy information to the rural communities, there is no proper channel through which this information can reach the rural community people. In most African countries there are no financial literacy programmes arranged to teach the resource-poor community people. Some Non-Governmental Organisations (NGOs) have financial limitations and often with different competing priorities. Therefore, Arya (2018) observes that there is a need for an appropriate information delivery mechanism to the disenfranchised and resource-poor community people, there is a need for a medium of information which has a wider coverage and can be more entertaining. In line with this view, previous studies have observed that one main channel that has been appreciated and highly ranked in terms of flexibility and easy access by community people is the radio. According to Kamba (2009), the value of financial literacy information in rural communities cannot be overemphasized because the information has become a supportive input for any development program and thus an appropriate channel must be put in place to deliver this information to the rural populace. It is so vital that is why Nyerere (1967) stated that "while other countries in the world aim to reach the moon, we must aim for the time being, at any rate, to reach the villages by providing them with necessary information". Nevertheless, in the context of Uganda, the effectiveness of audio media technology in the form of radio broadcasts and audio CDs has not been previously investigated. It is not known therefore, whether AMT can enhance the financial literacy knowledge levels of the community people. Therefore, this study sought to achieve this aim by using radio broadcasts and audio CDs as a channel of communicating financial literacy lessons to the Radio Listening Club members (RLCMs). This article is organized as follows: It begins with an introduction that provides an overview by laying out the background to the study, this is followed by theoretical underpinning and literature review. The next section highlights the methods of use in the study. The last two sections address the key study results and discussion of the major findings and implications.

\subsection{Theoretical background and literature review}

Previous studies, for example, Lusardi and Mitchell (2014) suggest that the traditional economic strategy to consumption decisions and saving suggests that well-informed and rational individuals will consume much less than their incomes when their earnings increase, and they will at all costs make savings to support consumption when income falls. Also, this study indicates that theoretical models that deal with consumers' behavior and reflecting on the economic environment subtly indicate that individuals are able to formulate and carry out savings and cut down expenditure plans. The study suggests that all that requires proficiency in financial management for example knowledge of purchasing power and the ability to effect difficult economic calculations and decisions. However, a reflection of the literature on financial literacy, unfortunately, shows very low knowledge levels almost on all parameters used to measure 
financial literacy among the population both in developing and developed countries. Low knowledge levels are reflected across gender, age, socio-economic status, and other key demographic characteristics. Addressing this situation requires the concerned countries taking initiatives of financial literacy education programmes for their population. Nevertheless, this comes with costs which deter financial literacy education efforts, especially for poor-resource countries. This being the case, there is need therefore, for a less cost-effective, flexible and conducive medium for the circulation of financial literacy education programmes to communities. There is need to use the readily available ICTs in our communities to reach the rural population, for example, one study agrees with previous studies that radio especially when combined with other media such as audio CDs and video CDs is the mass communication technology that can reach the wider audience throughout the world. It beats barriers of electricity, internet, bad terrain, etc. It is cheap and thus affordable even by the poorest of the poor in the community (Delavande, Rohwedder \& Willis, 2008). However, it should be noted that even if there is a considerable theoretical and empirical body of work on the use of audio media as a medium of information dissemination, less attention has been given to its effectiveness in enhancing knowledge levels of individuals as regards financial literacy. As shown in the proceeding sections, this has been the major aim of this research. In their study Lusardi, Michaud and Mitchell (2011) they present a simple two-period model of portfolio allocation and consumer saving regarding risky stocks and safe bonds, and risky stocks, permitting for the attainment of human capital in the form of financial literacy knowledge. This work suggests that individuals wilfully decide to invest in financial knowledge to gain access to higher-returns in form of assets. Such financial literacy training enables them to identify better-performing assets instead of hiring financial advice-givers who can considerably reduce their investment expenses. The desire for financial knowledge by individuals is also expressed in another study by Hanemann and Scarpino (2016) where they assert that individuals do not only require capital market investments but also have a desire to invest in financial knowledge. Additionally, this study observes that even if some individuals may not invest anything in financial knowledge it is still important to note that raising financial knowledge for everyone earlier on in life is crucial. This is required so that even if individuals with low education levels decide not to invest again, they will still earn considerable savings which in turn will significantly improve their wellbeing. Study findings also indicate that socio-demographic characteristics of individual affect their knowledge of financial literacy, for example, it is observed that an individual's income level declines from the mid-50s to retirement. The study adds that income significantly falls on retirement, reflecting the fact that labour earnings far more surpass social security and pension scheme benefits (Lusardi, Michaud and Mitchell, 2011). Similarly, Njuguna and Otsola (2011) disclose that knowledge acquisition in financial matters significantly differs across demographic characteristics. Since different studies are conducted in different contexts, it is thus vital to investigate the influence of these demographics on the uptake of financial literacy knowledge.

\subsection{Effectiveness of audio media technology in equipping community people with financial literacy knowledge}

The study by Kamba (2009) observes that access to various information communication services has become more difficult especially for the rural and resource-poor peasants. Such categories of people have limited individual means of becoming literate, due to their characteristics such as 
being illiterate, too young, too old, too poor or too ill because of the economic and information poverty that they experience. This view is supported by Chester and Neelameghan (2006) who points out that a big percentage of the populace in most rural communities in Africa have not had their information and developmental needs sufficiently met, neither by the government nor by the NGOs. Therefore, it is imperative to investigate whether audio media technology in the form of radio broadcasts and audio CDs can be of significant help regarding knowledge acquisition in financial literacy. Radio has been considered a suitable medium for the transmission of financial literacy programmes because the population in the rural setting regardless of their socioeconomic status can afford to own a radio. In addition, today more than ever before community radio stations are widespread, transmitting into even the remotest villages. Consequently, disseminating information using radio broadcasts, audiotapes or audio CDs can be an effective method and can quickly enhance knowledge levels of the community people regarding financial literacy. Moreover, financial information in newspapers, magazines, newsletters or journals can easily be converted into the local languages and transmitted to specific targeted ethnic audiences (Toussaint-Comeau and Rhine, 2000). The author further shows that radio information can easily and quickly reach everyone without any encumbrance, it can even reach the rural elderly who may be experiencing greater mobility limitations. Radio could be appropriate because other information delivery mechanism such as workshops have been despised by previous research. For example, Hanemann and Scarpino (2016) argue that when workshops are used as a medium for financial literacy information, they only benefit individuals who intentionally seek for financial instruction leaving behind majority community people who usually are most in need of this financial literacy information. Therefore, given this situation, there is a need for innovative and easily accessible means for the dissemination of financial information to the rural-based community people. Although radio has been identified by earlier research as the most appropriate medium for the dissemination of financial literacy information, its effectiveness in this regard and particularly in the Ugandan context has not been sufficiently investigated.

Findings of the study conducted by Spader et al. (2009) shows that using the media particularly radio as a medium of communicating financial literacy information is very effective. In their study, they found that half a year after the financial literacy program was broadcasted, listeners of Viva Seguro radio significantly increased their knowledge on the type of risks they could be subjected to and their perceived capability to identify and deal with such risks. Results also indicated that their knowledge regarding the number and kind of insurance products available on the market also increased. One study pointed out the possibility of arranging financial literacy public campaigns, however, the authors were skeptical of how this campaign would be arranged. Nevertheless, they pointed out that public campaign would be vital in the promotion of financial literacy by circulating credible and reliable palatable, extensive, complete, timely and continual financial literacy information (Rodriguez, Sánchez \& Zamora, 2016). In developing countries where technological development is at its infant stage, the connection between technology and financial products has demonstrated to be a vital pillar for the firm and individual success. This connection of technology and financial literacy products offers a central tie on the promotion of financial literacy education (Gale \& Levine, 2010). In another study, it is indicated that individuals who experience little financial literacy information and education normally rely on informal financial systems which are within their access. However, this barrier can be overcome by employing information communication technology such as phones, TVs and radio. These do not only give a feasible option to reduce operational costs but can go a long way in creating user- 
friendly and suitable platforms for users (Mabula \& Ping, 2018). However, what remains unclear is whether these ICTs are effective tools in enhancing the literacy knowledge levels of the community people. This paper set out to carry out that investigation as shown in the results section.

Previous research has warned against selecting a channel for the dissemination of financial literacy programmes to the communities without assessing its effectiveness. For example, Bansal (2014) observed that it is imperative not to base a strategy of communicating financial literacy around a wider coverage-that the channel can reach as many people as possible without bearing in mind the effectiveness of the selected methods. Strategies such as financial literacy education in schools, use of radio, TVs and other media, drama, outreach programmes to communities, financial education in workplaces, etc. All these should be assessed for their effectiveness before employing them in any financial education endeavour. This study adds that radio is particularly an effective medium of communication in Uganda, its effectiveness has not been sufficiently assessed in the previous studies. Nevertheless, given the fact that a high percentage of the population owns, and uses, a radio. - radio compared to other media has been found to be a cost-effective means of reaching large numbers of rural people.

\subsection{Knowledge levels regarding financial literacy between members who listened from RLCs and those who listened individually}

Scholars have found RLCs to be very effective in assisting participant members to gain knowledge of the broadcast content. For example, one study noted that often the clubs discuss a recorded radio programme, first listening to the recording, and then there is the discussion, which is divided into two parts. First, the members discuss the relevance of the information, and then how to make use of the information locally. The youth interviewed in this study felt that their discussions of other clubs' programmes that had been broadcast on the station provided a good way to learn from nearby communities and villages, the youths felt that their knowledge had significantly increased (Mchakulu, 2007, p.256). In a related study, communication and information are pointed out as benefits of RLCs, information on several community aspects that touch on the lives of members is not only easily delivered to members through RLCs, but this information is discussed and actions for implementation suggested. Sharing information and ideas has a direct impact especially on the most marginalised through improving their livelihoods (Fao Dimitra Project Report, 2011). The study adds that RLCs are even more crucial for women as a way of reducing their isolation and exclusion from developmental programmes and providing them with a means for receiving information and acting on it. The same study shows that if the information is the gold of the 21st century, then the community listeners' clubs are deposits waiting to be mined. Similar sentiments are raised by earlier authors who report that RLC methodology in Zambia and Malawi greatly improved the lives and welfare of the rural women. Besides, they were empowered to challenge their long-held domination by their husbands. Economically, the women were able to take charge of their own earned income and decide what to do with it and as such the women became self-confident and self-reliant (Warnock, 2001; Banda, 2007).

While emphasizing the importance of RLCs, one author indicated that RLCs if well planned and organized, they have the possibility of bringing about community infrastructure development. RLCs enlighten and teach the community members to be self-reliant in the management of their 
problems. They act as a voice for the voiceless members of the community who have no other platform to express their views (Manda, 2015). The study adds that since the RLCs seem to influence social change, awareness, attitudinal change and development, the study endorses the formation of RLCs for radio-based communication for development interventions. Relatedly Mhagamaa (2015) argues that RLCs can change the lives of the rural poor for the better, because the information they receive, share, and discuss and implement from the radio broadcasts can empower them not only to make informed decisions but to be knowledgeable on issues that affect their daily lives. The study further notes that RLCs act as a forum for ordinary people not only to receive information from the government and other development agencies but also to give their views, opinions, and feelings. Based on these arguments and relevance associated with RLCs, it is not known therefore, whether members who listen to the radio broadcasts individually can benefit from the programmes in the same way as members at the RLCs, partly this research was motivated by this idea.

\subsection{The relationship between individual's socio-demographic characteristics and financial literacy}

\subsubsection{Relationship between gender and financial literacy}

In the study by Schwella and Nieuwenhuyzen (2014), it is indicated that some countries need to double their effort and take affirmative action for women particularly to ensure that women are not left behind regarding financial literacy as is always the case in most countries. In the 14 countries where the study was conducted women were found to have lower levels of financial knowledge than men in almost every country studied. In a related study by Lusardi and Mitchell (2008) grownup women in the United States of America exhibited truncated levels of financial literacy even in the most basic financial information. The study observed that even most women had not undertaken retirement planning, given the fact that financial knowledge and financial planning are closely related. More so, women who demonstrate higher levels of financial literacy understanding are more likely to plan and be successful than those who do not. Previous studies have established that women more than men have low levels of financial literacy and all these studies seem to suggest that, there is a need for constant information flow to this segment of the population if their financial literacy levels are to be uplifted. Study findings of Fletschner and Kenney (2014) indicate that even when rural women have access to financial literacy information, they may not be in a position to process and comprehend it because of their lower levels of education and lack of exposure to other languages. This hinders women to benefit directly from financial literacy information that is given in writing or in other dialects other than those they speak in their respective neighbourhoods. In addition, this study observes that in settings where women are segregated as regards ownership of the property because it is only men who are perceived as sole breadwinners for their families, women's ability to offer a family asset as collateral say for a bank loan and their interest to invest in productive activities is inhibited. This situation makes women be perpetual dependants on men regarding financial literacy decisions. This is supported by findings of another study that pointed out that in situations where traditions and socio-cultural norms limit women's free movement and their association with other community members especially those of the opposite sex, women's chances of attending formal financial literacy trainings are curtailed and in general their access to information is compromised (Primo \& Khan, 
2003). Similarly, another study by Fletschner, Guirkinger, and Boucher (2010) observed that 15\% of women surveyed in Paraguay said that they were unable to access credit facilities even though their husbands indicated to have direct access to credit. Hence, the supposition that married women can receive support from their husbands to overcome gender-specific obstacles is not true and henceforth disputed. Findings of the study by Fletschner and Kenney (2014) show that women are more risk-averse compared to men, and thus without adequate assurance of insurance women are less likely to obtain loans from any financial institution. The fact that women are risk-averse, they have a stronger preference for financial products that do not require collateral which is not common in the current business. This is consistent with OECD (2013) where it is observed that more women than men exhibit relatively low levels of financial knowledge and skills. Women have several shortcomings even if they have demonstrated to be better in financial literacy management behavior in the short term. For example, unlike men, women have high chances of facing difficulties in savings and personal financial management. Also, as mentioned in the preceding paragraphs women, more than men are risk-averse and will tend at all costs to avoid business ventures that require taking risks. Although there are gender differences regarding knowledge levels of financial literacy, there were no noticeable differences between gender and financial behaviours. This is perhaps because most financial behaviours are exercised at family level for example, choosing products, saving, investment, loan acquisition, etc. while financial knowledge is wholly at the individual level (Chen \& Volpe, 2002). Besides, gender differences in financial knowledge may be due to historical gender disparities. This being the case it is most likely that gender differences in financial knowledge among the young generation exposed to the equal environment are smaller.

\subsubsection{Relationship between age and financial literacy}

A growing pool of literature shows the relationship between an individual's age and financial literacy knowledge, for example, Monticone (2010) points out that there is some verified proof of an inverse U-shaped age profile of financial literacy knowledge of most basic financial literacy aspects. This indicates that middle-aged adults report higher financial literacy scores compared to their younger and older counterparts. The raise in financial literacy scores might be due to increased experience while the consequent decline could perhaps be because of deteriorating mental drops. A related study by Lusardi (2003) indicates that there is a conspicuous difference in financial literacy knowledge levels by age. The study observed that in most countries surveyed the middle-aged respondents demonstrated higher levels of financial literacy than the youngest and oldest participants. However, one study by Chen and Volpe (2002) presents contradictory findings where it observes that there are interceding factors that may negatively affect financial literacy knowledge levels of the old. The study notes that the old people with vast experience of different financial aspects may find it problematic to match the ever-growing financial developments in the market place including but not limited to the introduction of technology, new financial regulations, and new financial products on market. The study adds that mental corrosion of the old people may significantly affect their ability to comprehend, retain and apply new financial knowledge. Another study by Finke, Howe, and Huston (2016) supports these findings, the study found a persistent linear decline in financial literacy scores of individuals aged 60 years and beyond. It was observed that scores obtained from all the 16 questions administered significantly declined with age. This study further notes that the age-related decline in financial 
literacy scores is nearly the same in all the four financial topic areas that were included in the survey. This persistent decline in financial literacy knowledge is perhaps due to the gradual mild cognitive loss that comes with old age.

Furthermore, the claim that old people's experience helps them to make correct financial decisions is disputed by Hibbard et al. (2001) where they found that despite their experience, old Medicare beneficiaries had more chances of making financial errors when interpreting health plan information compared to the younger subjects. This indicates that age is closely associated with financial literacy knowledge gain or lose. More search found age to be a predictor of financial literacy knowledge, for example, Agarwal et al. (2009) shows that old age negatively affects financial decision-making ability. The study observes that when borrowers exceed 50 years of age, their quality of credit decisions starts getting eroded. A similar study by Korniotis and Kumar (2011) also notes that even if there is improved investment scale among the aged individuals, this does not necessarily improve their investment performance, on the contrary, there is a significant decline in investment performance after and beyond 70 years of age.

\subsubsection{Relationship between education and financial literacy}

One study by Rooij, Lusardi, and Alessie (2011) observes that individuals who rely on the advice and help of family and friends for financial literacy information are mostly those with low levels of education. Such members are uninformed about the most important components of financial literacy such as personal savings, investments, budgeting, expenditure management, etc. This would not be the case if they relied on the professional advice given by financial experts such as bankers, certified public accountants, and other financial professionals. This is congruent with another study by Lusardi (2008) who points out that less educated people are low literacy individuals and are more likely to rely on friends and their family for financial advice whereas the more educated are likely to be financially sophisticated and they rely on newspapers, books, televisions, internet and other ICTs for financial information. Furthermore, previous research such as that of Cackley (2010) highlights that individuals who were privileged to attend or be exposed to financial literacy education programs while in high school were more likely to save later in life than their counterparts who have not been exposed to any financial literacy programs in their lifetime. Additionally, the same study observed that although it is not probable to turn low literacy individuals into financial literacy experts, it is viable to put in place financial literacy education programmes that focus on simple rules and good financial behavior. Such financial literacy programs should be so much simplified to meet the education standards of the target beneficiary groups. Furthermore, the study pointed out that in every study there are different and specific segments of the population-those with low education and usually with low income but also in the same population, there are more educated and affluent households. Therefore, this should be born in mind as education literacy programs are being designed and implemented. They should be tailored to their financial literacy needs.

One study observed that education levels of individuals affect their cognitive abilities which subsequently increases their confidence and participation in financial literacy matters. Higher levels of cognitive ability lead to greater financial market participation by individuals (Rodriguez, Sánchez \& Zamora, 2016). This study adds that educated individuals are more likely to increase their investment incomes compared to those who are not educated. Likewise, high school graduates have more chances of reporting high income from retirement saving than non- 
graduates. The study by Hogarth (2006) reports similar findings where it is observed that people in the United States of America with inadequate English-speaking proficiency are those with no or low levels of educational achievement and such low levels of education can negatively affect financial literacy. For instance, the Jump \$ tart Coalition survey indicated an association between the test scores of the basics of financial literacy and educational attainment levels of test-takers and their parents. In addition, Lusardi and Mitchell (2008) reports that researchers working with the Board of Governors of the Federal Reserve System from their findings of the reviewed consumer survey data from Michigan University found statistically significant association between participants' formal educational levels and their capability to answer correctly several true-false financial literacy questions covering but not limited to personal savings, credit facilities, investment, etc. Relatedly, one study by Lusardi, Michaud, and Mitchell (2017) observes that welleducated individuals are in most cases in a better position not only to set better economic goals but to make better and well-informed financial decisions for their families and themselves. Such individuals have high chances of securing better-paying jobs and are a desirable pool of labour for many employing companies and organisations. This is confirmed by another study that found higher levels of education to be positively and closely associated with not only a better comprehension of credit reports and credit scores but in general with higher levels of knowledge regarding financial literacy (Chen \& Volpe, 2002). Findings from the works of Bruhn, Ibarra, and McKenzie (2013) show that households with less education have fewer savings and fewer incomes as compared to highly educated households. The latter have higher motivations for savings due to the desire for the progress they have built over time. Given the fact that they have more, educated households have high regard for better financial management techniques and they rationally acquire higher levels of financial literacy education. Nevertheless, it should be mentioned that some studies found no association between education and knowledge of financial literacy, for example, Mundy and Masok (2011) in his study observes that some people achieved higher scores notwithstanding their low levels of education, this means that it is possible for people with low levels of education to acquire higher levels of financial literacy. Although today more than ever before, there is a growing need for access to financial knowledge, this desire is hampered by lack of appropriate channel through which financial information can trickle down to the common person. Owing to this fact, the main aim of this study was to evaluate the effectiveness of audio media technology in the form of live radio broadcasts and audio CDs in enhancing RLCMs' knowledge regarding financial literacy. An investigation of this kind has not been sufficiently handled by previous studies and in respect to the Ugandan context. And therefore, the following research questions are put forth to guide this study:

1. How effective is audio media technology in equipping RLCMs with financial literacy knowledge?

2. Are there differences in knowledge levels regarding financial literacy between members who listened from RLCs and those who listened individually?

3. Is there a relationship between financial literacy and individual's socio-demographic characteristics (with regard to gender, age and education)? 


\subsection{Methods}

\subsection{Study setting and design}

This study is part of a Ph.D. study investigating the usability and effectiveness of audio media technology in distance and community education in Uganda. This research aimed at assessing the effectiveness of AMT in enhancing RLCMs' knowledge regarding financial literacy. It involved 50 villages selected from four districts in the Rwenzori region of western Uganda. The selection of the members from each village was based on the following criteria: 1) Being able to access signals of Mountains of the Moon University (MMU) FM radio clearly and loudly, 2) Ready to join and be a member of a RLC, 3) Engaged in one or more socio-economic activity(ies) such as farming, diary, poultry etc. from which income is received, 4) and ready to listen to the live radio broadcasts on financial literacy aired on MMU FM radio. We obtained information regarding the radio transmission capacity and specific areas reached from the radio management at MMU. This was followed by conducting a baseline survey in May 2018, to establish the knowledge levels of participants regarding financial literacy. Data from this survey was analysed and two cohorts were identified. One cohort consisted of 157 (17\%) members who were found with relevant knowledge levels of financial literacy and the other cohort contained 782 (83\%) members who were found to have low levels of knowledge on even the most basic aspects of financial literacy. The first cohort was excluded from this research as the study would not add much to their knowledge. The study continued and focused on the 2nd cohort. This cohort was organised into 50 RLCs and a well-structured leadership was put in place consisting the chairperson, secretary, and time keeper. Researchers have pointed out numerous advantages of radio listening groups or forums, for example, one study by Mchakulu (2007) observes that radio clubs are helpful because members can discuss the content immediately after the broadcasts, but they also have a chance of making a follow up by listening to the recorded programme. In RLCs, members can discuss the relevance of the programme and then, more importantly, discuss how to make use of the information locally.

Financial literacy content was developed and broadcasted by two experts from the Department of Banking and development finance. The content was broadcast to the cohort that was found lacking knowledge regarding financial literacy. Each RLC was given a small radio set with batteries that were estimated to last for a month. They were also given a broadcast schedule and asked to follow the schedule and meet at an identified meeting place to listen to the radio broadcasts. The radio programmes lasted for a month and they were very interactive whereby the members from different RLCs were given a chance to call in and give their opinions on the programme or ask questions. To assist members, make a follow up on radio broadcasts, we recorded all the content about financial literacy on CDs and the CDs were distributed to all the RLCs in the 50 villages. This audio information was intended to assist the farmers either fully grasp the content or comprehend some aspects of the content that were missed or not understood during the live radio broadcasts. After two months, a period hoped to be long enough for the participants to have put in practice what they were taught, we conducted an end-line survey. As can be seen in the results section, baseline survey data was compared with end-line survey data to establish if there are any significant changes in knowledge levels before and after an intervention of AMT. 


\subsection{Participants}

A total of 939 participants were included in the current study drawn from the 50 villages of Kabarole, Kyenjojo, Bunyangabu and Kamwenge districts in Western Region in Uganda. Out of 782 respondents, 484 (62\%) were male while 297(38.0\%) were female. These results indicate that there were more males than females in this current study. This reflects the real situation of the Ugandan context where despite having more women than males in total population, women are rarely involved in development projects. Respondents were also asked to indicate their age and most respondents 254 (33\%) were aged 50 years and above. Those aged between 40 to 49 years were also slightly high $252(32.2 \%)$, those between 30 to 39 were slightly less $206(23.6 \%)$, and the least in number with $70(9.0 \%)$ were aged between 20 to 29 years. No participants were less than 20 years of age. Participants were also required to indicate their level of education and a half of them 391 (50\%) mentioned Primary level, while those who mentioned secondary were $257(32.9 \%)$, a small number $74(9.5 \%)$ mentioned tertiary and $60(7.7 \%)$ indicated to have not attained any level of education. Results on the marital status of respondents revealed that majority of the respondents of the study were married, consisting of 531 (78.4\%) as compared to a small figure of 145 participants $(21.4 \%)$ who were either married, separated, widowed or refused to answer. Marital status of the respondents is often considered an important variable because there may be a significant difference in terms of choosing radio programmes to watch between married respondents and those who are not. It is assumed that respondents who are married may not have time to watch the television programme regularly and mostly do the work in farming. Table 1 shows a summary of these and other demographic characteristics of participants:

Table1: A summary of demographic characteristics of the sample $(n=782)$

\begin{tabular}{l|lll} 
Characteristics & Categories & No & \%ge \\
\hline Gender & male & 484 & 62 \\
& & & \\
Age & female & 297 & 38 \\
& $20-29$ & 70 & 9.0 \\
Level of education & $30-39$ & 206 & 24 \\
& $40-49$ & 252 & 32.2 \\
& $\geq 50$ & 254 & 33 \\
& p/s & 391 & 50 \\
Marital status & sec. & 257 & 33 \\
& tertiary & 74 & 10 \\
& none & 60 & 9.9 \\
& & & 68 \\
& married & 531 & 20 \\
& single & 159 & 3.0 \\
& separated & 27 & 8.7 \\
& widowed & 59 & 0.9
\end{tabular}

Note: P/S- Primary, Sec- Secondary 
Source: Own based on Primary data

\subsection{Instruments and measurements}

This study used the Financial Literacy Measurement Survey (FLMS). This FLMS was developed with useful insights from the validated works of (Toussaint-Comeau,2000; Fletschner D, Kenney, 2014; Lusardi, 2004). However, in order to be contextually relevant, the rest of the items were self-developed. The instrument went through three levels of verification for correct wording, accuracy and clarity; First, it was checked and scrutinized by the authors of this paper, second it was given to a senior lecturer in the Department of Banking and Development Finance at MMU and third it was discussed in a pre-survey workshop involving authors, research assistants and two invited financial literacy experts from the School of Business and Management Studies at MMU. Comments and suggestions from the workshop and those obtained after the pilot study greatly improved the quality of the instrument. We tried to keep it short and precise so that the participants could not easily get tired and lose interest and end up giving wrong responses.

KoBoCollect was used in the actual data collection from respondents. Although it is widely used in humanitarian emergencies and challenging field environments, KoBoCollect is now widely being used in academic research because of its many advantages; it is environmentally friendly, instead of carrying hard copies of a questionnaire, you can create KoBoCollect forms on your computer and deploy them so that the research assistants can access them on their mobile devices. Data collection can be done using mobile smartphones, tablets, computers, etc. It minimises errors normally encountered using hard copies of questionnaires. Besides, there is no limitation on the number of forms, questions, or submissions one can make (including GPS points, photos, and other media) that can be saved on the mobile device. The instrument was administered by the lead author assisted by 9 research assistants. The instrument includes the following scales of measurement: Personal financial management, savings management, loan acquisition and management, investment management and financial service providers and making payments.

\subsection{Ethical Consideration}

Preceding data collection and all other research activities related to this study, all the participants were informed about the rationale of the study and were invited to participate. The research aims, and goals were also articulated and circulated in writing to all the Local Council 1 Chairpersons of the 50 zones. Participants were assured of their freedom to pull out of the study at any stage whenever they deemed it feet. Besides, they were assured of anonymity, they were told that nowhere would their names be singled out so that their responses can be personally identified. During data collection research assistants used codes that were assigned to participants ahead of data collection exercise.

\subsection{Data analysis}

The data used in this study was purely quantitative as such descriptive statistics were used to analyse demographic data of the respondents such as age, gender, level of education and marital status. Additionally, the assumption of homogeneities of variances was tested and satisfied via 
Levene's $F$ test, $F(525)=.522$. This was done as a basis of comparison for those who listened to the radio individually and those who listened from the RLCs. For research question 1 , the comparison in terms of means and standard deviation to assess the change in means before and after the intervention was performed and results showed a change in financial literacy knowledge after the intervention of audio media technology in form of radio broadcasts and audio CDs. For research question 2, we ran independent t-test to assess if they are significant changes between the two groups after the intervention of audio media. For research question 3, we also used a Two-way ANOVA to establish the relationship between demographic characteristics and financial literacy. The quantitative findings are discussed in the section that follows:

\subsection{Results}

\subsection{The effectiveness of audio media technology in equipping RLCMs with financial literacy skills.}

This objective intended to find out if there is a change in financial literacy knowledge of the participants after the intervention of audio media technology. We analysed the knowledge the respondents had before audio media intervention and the knowledge after the intervention. The results (see table 2) were analysed in line of (i) personal financial management, saving management, loan acquisition and management, investment management and financial service providers and making payments. For personal financial management apart from two items results show a change in means after the intervention of AMT. All the items had an increase of more than 0.5 scores, showing significance in paired t-tests with p-values .041 and .002 respectively which are below .05. For savings management, results showed that there is a change in the means before and after the AMT intervention (an increase of more than 0.5 scores). However, the $t$-tests run showed that these changes are not statistically significant showing p-values $.071, .069$ and .082. This means that those changes could have happened due to other reasons which this study did not identify. Results regarding loan acquisition and management indicate that the respondents' knowledge increased after AMT intervention an indication that after the intervention members were confident to acquire loans with a clear reason compared to the way the used to get them before. The t-test was done, and two items were found to be statistically significant and this could be attributed to AMT training. However, it was also realized that the increase in mean for Loan interest choice was not attributed to AMT rather attributed to other factors ( $p$-value was .071). Regarding investment management items were analysed before and after the AMT intervention and two items showed a positive change of an increase of more than 0.5 scores while the rest did not show a big increment. Data were therefore analysed using paired t-tests to know the level of increment for those items with high increase and found out to have $p$-values $0.03(<0.05)$ and $0.004(<0.01)$ respectively. Therefore, it can be concluded that the AMT intervention played a big role to change the way people have been investing specifically to know which enterprise to invest their money and also the expectations regarding investment returns. Lastly results on financial service providers and making payments revealed that out of the five items two had shown an increase of more than 0.5 scores while others were below. The t-test was applied to know the level of significance in the change of means and it was found out that only two items (saving with banks and procedure for choosing the financial product) had $p$-values 
being respectively .0034 and .0041 . Therefore, in general, the financial literacy items which showed a significant increase in mean after AMT intervention in the form of radio broadcast and audio CDs have at the same time shown a significant change in t-tests with p-values less than .05. Meaning that the changes observed afterward are largely attributed to the intervention.

Table 2. Effectiveness of audio media in equipping RLCMs with financial literacy knowledge.

\begin{tabular}{|c|c|c|c|c|}
\hline $\begin{array}{l}\text { Sr. } \\
\text { No }\end{array}$ & Practices & $\begin{array}{l}\text { Before } \\
\text { Mean (SD) }\end{array}$ & $\begin{array}{l}\text { After } \\
\text { Mean (SD) }\end{array}$ & $\begin{array}{l}\text { Change } \\
\text { in Mean }\end{array}$ \\
\hline \multicolumn{5}{|c|}{ Personal financial management } \\
\hline Pfm & Planning household expenditure & $1.79(.47)$ & $2.81(.78)$ & -0.01 \\
\hline Pfm & If unemployed how to make a living & $1.93(.69)$ & $2.04(.76)$ & 0.11 \\
\hline Pfm & Does your hold have a budget? & $2.23(.71)$ & $1.98(.87)$ & -0.25 \\
\hline Pfm & Items included in a budget & $2.75(.78)$ & $3.56(.95)$ & $.81^{*}$ \\
\hline Pfm & Managing household revenues & $2.14(.67)$ & $2.11(.99)$ & -.03 \\
\hline $\mathrm{Pfm}$ & Sources of income & $1.06(.62)$ & $1.85(.83)$ & $.79^{*}$ \\
\hline \multicolumn{5}{|c|}{ Savings Management } \\
\hline Sm & Monthly savings & $1.48(.73)$ & $2.37(.615)$ & $.89^{* *}$ \\
\hline $\mathrm{Sm}$ & Where to save money & $1.98(1.03)$ & $2.71(.97)$ & $.73^{\star \star}$ \\
\hline $\mathrm{Sm}$ & Reasons for saving & $1.39(.787)$ & $1.97(.71)$ & $.58^{* *}$ \\
\hline Sm & Safety of saving with banks & $1.81(.81)$ & $2.31(.54)$ & 0.55 \\
\hline Sm & Safety of saving at home & $1.11(.79)$ & $2.36(.89)$ & 1.2 \\
\hline \multicolumn{5}{|c|}{ Loan acquisition and management } \\
\hline Lam & Loan sources & $1.445(.93)$ & $1.735(.76)$ & .29 \\
\hline Lam & Loan interests choice & $2.41(.98)$ & $1.58(.85)$ & $-.82^{* *}$ \\
\hline Lam & Purpose for obtaining the loan & $1.55(.67)$ & $2.41(.72)$ & $.86^{* *}$ \\
\hline Lam & Buying on discount & $1.93(.62)$ & $1.87(.55)$ & -.06 \\
\hline Lam & Taking a loan without major reason & $2.31(.85)$ & $2.01(.73)$ & -.13 \\
\hline \multicolumn{5}{|c|}{ Investment management } \\
\hline $\mathrm{Im}$ & Enterprise in which you invested your money & $1.07(.71)$ & $1.77(.64)$ & $.53^{\star \star}$ \\
\hline Im & Expectations regarding investment returns & $1.06(.69)$ & $1.75(.83)$ & $.69^{*}$ \\
\hline $\mathrm{Im}$ & Expectations on investment returns & $1.28(1.27)$ & $1.23(1.15)$ & .37 \\
\hline Im & $\begin{array}{l}\text { If someone buys livestock, it is only an } \\
\text { investment if one intends to obtain future } \\
\text { income from it. }\end{array}$ & $2.34(1.25)$ & $2.21(.96)$ & -.13 \\
\hline \multicolumn{5}{|c|}{ Financial service providers and making payments } \\
\hline Fsp & $\begin{array}{l}\text { Saving with banks is better that other } \\
\text { institutions }\end{array}$ & $1.81(1.21)$ & $2.72(.63)$ & $.91^{*}$ \\
\hline Fsp & Reason for the choice of financial providers & $1.14(.49)$ & $1.97(.40)$ & .28 \\
\hline Fsp & Procedure for choosing your financial product & $1.30(1.08)$ & $1.95(1.04)$ & $.65^{*}$ \\
\hline Fsp & Asking about the banker's products & $1.45(.63)$ & $1.32(.76)$ & -.13 \\
\hline
\end{tabular}




\begin{tabular}{|l|l|l|l|l|}
\hline Fsp & Procedure for choosing financial product & $2.35(.57)$ & $1.98(.87)$ & -.37 \\
\hline & Valid N (listwise) & & & \\
\hline
\end{tabular}

${ }^{*}$ Significance at $p$-value $<.01,{ }^{* *}$ Significance at $p$-value $<.05$

Source: Own based on Primary data

\subsection{Knowledge levels regarding financial literacy between members who listened from RLCs and those who listened individually}

As it can be seen in table 3, the two groups compared (respondents who listened from RLCs and those who listened individually) to the radio programme on financial literacy were sufficiently normal for conducting a t-test (i.e, skew |2.0| and kurtosis <|9.0|; (Kundi et al., 2010). Additionally, the assumption of homogeneities of variances was tested and satisfied via Levene's $F$ test, $F$ $(525)=.522, p=.512$ for savings between RLCs and individually; $F(319)=.022$ with $p=.883$ for Loan Acquisition and mgt between RLCs and individually; $F(632)=.398, p=.470$ for investment between RLCs and individually; $F(566)=.3 .81, p=.051$ for financial service providers between RLCs and individually; $F(477)=2.23, p=.049$ for personal financial management between RLCs and individually. The tests of variances between those who listened via their clubs and those who listed individually indicate that the two groups being compared are assumed to be approximately equal $(p>.05)$. The independent samples t-tests were run and found to be $t$ $(525)=.422, \mathrm{p}<.05 ; \mathrm{t}(319)=.987, \mathrm{p}>.05 ; \mathrm{t}(622)=-.763, \mathrm{p}<.05 ; \mathrm{t}(566)=.563, \mathrm{p}>.05 ;$ and $\mathrm{t}(476)=-.838, \mathrm{p}<.05$ for savings, loans acquisitions and management, investment, financial service providers and personal finance accordingly. It was discovered that the listenership at the RLCs and listenership at individual level showed a statistically significant difference only in three areas namely: savings, investment, and personal financial management. In other domain like loans acquisitions and financial service providers, there was no observable difference regarding financial literacy knowledge levels in either group (Those who listened at the RLCs and those who listened individually).

Table 3: Knowledge levels between members who listened from RLCs and those who listened individually

\begin{tabular}{|c|c|c|c|c|c|c|c|c|c|}
\hline \multirow[t]{2}{*}{ Financial Skills } & \multirow[t]{2}{*}{$F$} & \multirow[t]{2}{*}{ Sig. } & \multirow[t]{2}{*}{$t$} & \multirow[t]{2}{*}{$d f$} & \multirow[t]{2}{*}{$\begin{array}{l}\text { Sig. (2- } \\
\text { tailed) }\end{array}$} & \multirow[t]{2}{*}{$\begin{array}{l}\text { Mean } \\
\text { Diff. }\end{array}$} & \multirow[t]{2}{*}{$\begin{array}{l}\text { Std. E. } \\
\text { Diff. }\end{array}$} & \multicolumn{2}{|c|}{$\begin{array}{l}\text { 95\% Confidence } \\
\text { Level }\end{array}$} \\
\hline & & & & & & & & Lower & Upper \\
\hline $\begin{array}{l}\text { Savings between } \\
\text { RLCs and } \\
\text { individually }\end{array}$ & .430 & .512 & .422 & 525 & .043 & .05770 & .13685 & .2111 & .3265 \\
\hline $\begin{array}{l}\text { Loan acquisition } \\
\text { between RLCs and } \\
\text { individually }\end{array}$ & .022 & .883 & .987 & 319 & .324 & 19982 & .20244 & .1984 & .5981 \\
\hline $\begin{array}{l}\text { Investment between } \\
\text { RLCs } \\
\text { and individually }\end{array}$ & .522 & .470 & -.764 & 632 & .044 & .08922 & .11672 & .3184 & .1399 \\
\hline
\end{tabular}




\begin{tabular}{lllllllllll}
4 & $\begin{array}{l}\text { Financial Service } \\
\text { Providers between } \\
\text { RLCs } \\
\text { and individually }\end{array}$ & 3.81 & .051 & .563 & 566 & .573 & .06965 & .12365 & .1732 & .3125 \\
$5 \begin{array}{l}\text { Personal finance } \\
\text { between } \\
\text { RLCs and } \\
\text { individually }\end{array}$ & 2.23 & .049 & -.838 & 477 & .040 & .14313 & .17072 & .4785 & .1923 \\
\hline
\end{tabular}

Source: Own based on Primary data

\subsection{The relationship between individual's socio-demographic characteristics financial literacy}

We analysed if there is a relationship between demographic characteristics in regard to age, gender, and education of participants and their uptake of financial literacy knowledge. The Levene's Test of Equality of Error Variances was done for all financial literacy themes "see table 4. Two way ANOVA was performed thereafter and found out, $F(1,456)=.045, p=.83$, partial $=.000$, observed power $=.055 ; \mathrm{F}(4,456)=.624, \mathrm{p}=.035$, partial $=.011$ with observed power $=.205$ age and $F(3,456)=1.04, p=.37$, partial $=13.54$, observed power $=.285$ for gender, Age and level of Education accordingly. Therefore, results show that there is no association between gender, level of education and financial literacy. However, there was a relationship between age (40-49 years and financial literacy. Regarding savings management a Two way ANOVA was done and found out, $\mathrm{F}(1,501)=.96, \mathrm{p}=.33$, partial $=.002$, observed power $=.165 ; \mathrm{F}(4,501)=$ $1.27, p=.30$, partial $=.005$, observed power $=.380$ and $F(3,501)=.073, p=.97$, partial $=.003$, observed power $=.063$ for gender, age and education level respectively. Thereafter, there was no relationship observed between demographic characteristics (gender, age and education) and financial literacy in terms of savings. For the relationship between loans acquisition and demographic characteristics results of a Two way ANOVA were found to be $F(1,294)=2.286$, $\mathrm{p}=.13$, partial $=.001$, observed power $=.326$ for gender; $\mathrm{F}(4,294)=2.017, \mathrm{p}=.09$, partial $=.017$, observed power $=.601$ for age and $F(3,294)=4.092, p=.007$, partial $=.006$, observed power $=.844$ for level of Education. Therefore, apart from level of education for participants aged between 30-39 years there is no association between gender and age and loan acquisition and management. The analysis for Gender and investment management using Two way ANOVA showed, $F(1,611)=.022, p=.88$, partial $=.000$, observed power $=.053$ while the age and level of education were $F(4,611)=.55, p=.701$, partial $=.005$, observed power $=.184$ and $F(3,611)=$ $.074, p=.97$, partial $=.003$, observed power $=.063$ respectively. These results show that the three demographic variables; gender, age and level of education have no association with financial literacy in terms of loans acquisition and management. Lastly to find out if demographic characteristics (gender, age and level of education) are associated with financial literacy in regard to financial service providers we run a two Way ANOVA test which showed $F(1,545)=.043$, $\mathrm{p}=.83$, partial $=.000$, observed power $=.055 ; \mathrm{F}(4,545)=.278, \mathrm{p}=.89$, partial $=2.43$, observed power $=.112$ and $F(3,545)=.035, p=.99$, partial $=1.25$, observed power $=.056$ for gender, age and level of education respectively. Therefore, demographic characteristics and financial literacy in terms of financial service providers have no close association. 
Table 4: Two Way ANOVA Table showing the relationship between socio-demographic characteristics and financial literacy

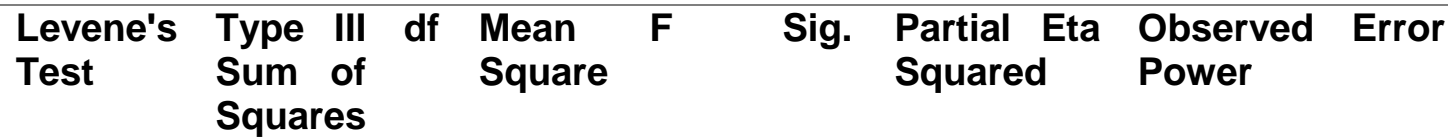

\begin{tabular}{|c|c|c|c|c|c|c|c|c|c|}
\hline 1.PFM & .007 & & & & & & & & \\
\hline Sex & & .156 & 1 & .156 & .045 & .83 & .000 & .055 & 456 \\
\hline Age & & 8.75 & 4 & 2.19 & .624 & .035 & .011 & .205 & \\
\hline Education level & & 11.04 & 3 & 3.68 & 1.04 & .37 & 13.54 & .285 & \\
\hline 2.Savings mgt & .455 & & & & & & & & \\
\hline Sex & & 2.35 & 1 & 2.35 & .96 & .33 & .002 & .165 & 501 \\
\hline Age & & 11.85 & 4 & 2.96 & 1.27 & .30 & .005 & .380 & \\
\hline Education level & & .538 & 3 & .18 & .073 & .97 & .003 & .063 & \\
\hline 3.LAM & .134 & & & & & & & & \\
\hline Sex & & 6.81 & 1 & 6.80 & 2.286 & .13 & .001 & .326 & 294 \\
\hline Age & & 24.04 & 4 & 6.01 & 2.017 & .09 & .017 & .601 & \\
\hline Education level & & 36.57 & 3 & 12.19 & 4.092 & .007 & .006 & .844 & \\
\hline 4.Investment mgt & .015 & & & & & & & & \\
\hline Sex & & .048 & 1 & .048 & .022 & .88 & .000 & .053 & 611 \\
\hline Age & & 4.66 & 4 & 1.16 & .55 & .701 & .005 & .184 & \\
\hline Education level & & .47 & 3 & .16 & .074 & .97 & & .063 & \\
\hline 5.FSP & .007 & & & & & & & & \\
\hline Sex & & .096 & 1 & .095 & .043 & .83 & .000 & .055 & 545 \\
\hline Age & & 2.43 & 4 & .60 & .278 & .89 & 2.43 & .112 & \\
\hline Education level & & .23 & 3 & .077 & .035 & .99 & 1.25 & .056 & \\
\hline
\end{tabular}

Note: mgt-Management, PFM-Personal Financial Management, LAM-Loans Acquisition and management, FSP-Financial Service Providers

Source: Own based on Primary data

\subsection{Discussion}

\subsection{Effectiveness of audio media technology in equipping RLCMs with financial literacy knowledge}

We analysed the knowledge levels of respondents before and after audio media intervention in personal financial management, saving management, loan acquisition and management, investment management and financial service providers and making payments. For most of the items under these scales, they showed an increase in means after respondents received the AMT intervention. An indication that although they had poor initial knowledge on most financial literacy aspects, their knowledge significantly changed after attending the AMT training. The increase in the knowledge levels does not surprise us because the participants were not only enthusiastic with AMT training but were very excited with the content on financial literacy; quite several participants indicated that this programme was the first of its kind. This coupled with our design of RLCs where members had an opportunity to discuss the content after each broadcast, could indeed have enabled them to grasp the content included in the training. Our findings are supported by Spader et al. (2009) who shows that the media particularly radio as a medium of 
communicating financial literacy information is very effective. In their study, they found that half a year after the financial literacy program was broadcasted, radio participants significantly increased their knowledge on the type of risks they could be subjected to, their perceived capability to identify and deal with such risks and their knowledge regarding the number and kind of insurance products available on market. Our findings also show that for the items where the means increased after the intervention, the t-tests similarly showed the differences to be statistically significant, which means that the differences realised after can be confidently attributed to the AMT. However, our findings also indicated that a few financial literacy items never showed significant changes because the mean scores before and after the intervention of radio broadcasts and audio CDs were not statistically significantly different and an indication that the intervention did not affect the knowledge levels of the participants on these very aspects. This could be due to personal preference where participants put more emphasis on some items at the expense of the others. Besides, this could also be due to the emphasis of the training whereby trainers during the broadcasts put more emphasis on the first three financial literacy themes namely; personal financial management, savings management, and investment management. No wonder these three came out positively whereby almost all the mean scores of items under these themes significantly increased after the intervention.

\subsection{Knowledge levels regarding financial literacy between members who listened from RLCs and those who listened individually}

The main aim of this article was to assess the effectiveness of audio media in equipping RLCMs with financial literacy skills. Participants were organised and listened to the radio broadcasts under RLCs. However, some participants due to reasons associated with their daily tasks could not make it to the RLCs and decided to listen individually. Given the fact that previous studies have attached much importance to RLCs by claiming that they are vital not only in enhancing knowledge levels of participants but improving their welfare and changing their poverty-stricken lives (Mhagamaa, 2015). Therefore, this study in part sought to find out the differences in knowledge levels regarding financial literacy between members who listened from RLCs and those who listened individually. Results showed that the listenership at the RLCs and listenership at individual level showed a statistically significant difference only in three areas; savings, investment, and personal financial management. Members who listened from the RLCs appeared to have more knowledge in financial literacy on savings, investment, and personal financial management, unlike their counterparts who listened individually. The reason for this could be attributed to the rigorous discussions that members carried out amongst themselves. Also, these being core aspects of financial literacy more explanations and illustrations were covered in the audio CDs which were distributed to the RLCs and members had additional sharing and discussion of the audio content. So, the members who listened independently could not have accessed these CDs and thus affecting their knowledge levels. This view is supported by one author whose study implemented health-talk radio programmes through RLCs and participants indicated that they gained a lot through discussions, they mentioned that RLCs have the potential to improve knowledge about health, medical research and improve presentation at health-care providers especially if the content is developed in response to listeners' needs (Nyirenda et al., 2018). This view was even held by an earlier study by Mhagamaa (2015) who argued that due to low literacy levels among community people, some of them are unable to comprehend some 
aspects broadcast on the radio station. Therefore, through sharing information and pooling knowledge in their RLCs, public deliberation can transform individuals' understanding and not only enhance their grasp of complex problems but be able to take practical steps in changing their lives. In other realms like loan acquisition management and financial service providers, there was no any observable difference regarding financial literacy knowledge levels in either group (Those who listened at the RLCs and those who listened individually). The reason for this finding is perhaps because, these two aspects, although were handled during the radio broadcasts, the emphasis was put on members finding ways to develop their capital base and avoid relying on the acquisition of loans from financial institutions. This information could have been grasped and understood in equal measure by members in either group and taken as such without members making extra efforts to understand these aspects.

\subsection{Relationship between individual's socio-demographic characteristics and financial literacy}

We analysed if there is a relationship between demographic characteristics such as age, gender, and education of RLCMs and their uptake of financial literacy knowledge. Results indicate that age is associated with financial literacy regarding personal financial management. Older participants aged between 40 to 49 years of age demonstrated more knowledge in personal financial management compared to the young participants. However, there was no relationship between age and other financial literacy themes. Education and gender are not associated with personal financial management. The association between age and personal financial management is not surprising, because naturally as people become adults unlike the young, they start thinking more about the future and change their life styles. It is possible that at this age they are more keen on how to properly manage their personal finances perhaps for saving and future investment. They think of what they will do during retirement, they think of how their children and other dependents will survive when they are dead. It is possible that such thoughts motivate them to manage their finances well. Results showed no association between age and loan acquisition, savings, investment and financial service providers. This is perhaps because of the many available opportunities for both the young and adult members of the community. Whereas adults can access loans from banks and other financial institutions, the government of Uganda provides a youth development fund which can be borrowed by the youth without security and at the lowest interest rate possible. This resonates well with one study that indicates that young adults today have diverse borrowing opportunities and access to a wide range of financial services even before officially entering the job market (Scheresberg, 2013).

Regarding the correlation between gender and financial literacy knowledge, our results surprisingly and contrary to the vast body of literature, showed no relationship between gender and their financial literacy knowledge. Therefore, there is no indication that a given group of gender either males or females has a comparative advantage over the other regarding financial literacy knowledge. Reasons for this could be two-fold; first, our financial literacy radio training programme catered for both male and female in equal measure, both were accorded equal chance of training and perhaps both could have benefited in the same way. Second, the circulation of audio CDs to both male and female participants coupled with the discussion of content under the RLCs could have benefitted both male and female in equal proportions. 
Although most of the studies on financial literacy found significant gender differences, our findings are supported by one study that found no statistically significant differences between males and females for records, savings, and investment financial literacy aspects (Falahati \& Paim, 2011). Although understanding gender differences is crucial in most studies, our results provide new evidence that depending on the study design and context, gender may not be a factor in the uptake financial literacy knowledge.

We also sought to establish the relationship between participants' level of education and financial literacy knowledge. Results show that apart from loans acquisition and management, generally there is no relationship between the level of education and financial literacy knowledge. This indicates that education is not associated with someone's financial literacy knowledge. In the context of this study, this could be explained by the fact that the radio training programme and the audio content on CDs was so much simplified without further technicalities for any person to understand irrespective of their education level. Another advantage is that the radio broadcasts and content on CDs were prepared in the native language of the participants giving a chance to all members literate, semi-literate and illiterate members. These reasons coupled with the fact that members of the RLCs had a chance to discuss the content amongst themselves education is rendered unimportant. Our results are in consonance with Chen and Volpe (1998) who observe that some people achieved higher scores notwithstanding their levels of education. For example, when evaluating students' knowledge levels on personal finance, they found that students, regardless of their level of education exhibited inadequate knowledge level, particularly regarding investments, this means that education is not associated with financial literacy knowledge. However, the association found between loans acquisition and education is not surprising because loan application will require some literacy and numeracy skills whereby loan applicants have to sign papers and be able to understand aspects of interests, reducing balance, penalties for defaulters Et cetera.

\subsection{Conclusion, implication and limitations}

Findings from this study point that evidences are found there is positive effectiveness of AMT in enhancing community peoples' knowledge. This study established that AMT in the form of radio broadcasts and audio CDs is very instrumental in assisting RLCMs uptake financial literacy information. Before the intervention of AMT participants had limited levels of financial literacy knowledge, however, it was established that their knowledge significantly increased following financial literacy training through radio broadcasts and audio CDs. We can conclude thus that given the low numeracy and literacy levels of most communities in Africa, AMT based on our findings emerges the best means of communication. Moreover, our research shows that the listenership at the RLCs and listenership at individual level differed only in three areas; savings, investment, and personal financial management. Although the difference was not across all the five themes, the results provide further evidence that RLCs are vital in complementing training via radio. This is because the RLCs do not only allow members to discuss but also to find ways of implementing the content. This view is supported by Monyozo (2008) who found that RLCs increases people's development knowledge, they are of considerable help in getting people to adopt better development practices. This is further corroborated by one study that shows that RLCs help members to decide on the appropriate actions to take after listening to the broadcasts, in away motivating people to solve their local community problems. Besides, the clubs help the community people to break down rural isolation and act as a public forum through which 
members' voices are heard (Rogers, Braun \& Vermilion, 1977). Furthermore, based on the findings of this study we conclude that although age is associated with financial literacy knowledge, this is not the case with gender and level of education when AMT is used as a means of information dissemination. We thus state that a general conclusion that there is or there is no relationship between demographic characteristics of individuals and financial literacy knowledge is not appropriate without considering the means used to disseminate information to the participants and without considering contexts. There will always be variations depending on study context and the media that is used to communicate information to participants.

Although this study has largely achieved its intended aims, it is not without limitations; first, there was a short period between intervention and the end line survey and given the fact that knowledge and skills may be put to use over long periods of time and should be evaluated only after a long time rather than a few months, this study may have yielded unrealistic results which should be applied with caution. Similar further studies should seriously consider an extended time between intervention and programme evaluation. Second, this study could have gained a lot from a mixed design approach, therefore the use of only quantitative method by self-reporting may not have given us in-depth insights about this study. This view is supported by Hastings and Mitchell (2011) who reported that individual self-reports and actual financial decisions do not always correlate strongly. Nevertheless, this study makes a useful contribution, as it differs from other researches in the financial education literature because of the depth and extent of content provided to the participants through AMT. Whereas the majority of previous studies analyse and handle financial literacy programs by picking one of a few aspects from the major financial literacy topics. Our study handled all the major financial literacy themes; Personal financial management, Savings management, investment management, loan acquisition, and management and financial service providers and making payments. Knowledge levels of participants were assessed on all the mentioned themes, thus covering a wide knowledge base of financial literacy information.

This study found that although some members of the RLCs receive incomes from bricklaying, retail businesses, charcoal burning, socio-economic grant for old people from government, a big number of them $79.7 \%$ derive their main source of income from agricultural produce, this, therefore, is an eye-opener to the government and other agencies involved in rural development not only to invest in agriculture but design agricultural financial literacy training programmes for the rural poor so as to boost their incomes and livelihoods. The results of this study can be a point of reference in choosing an appropriate technology to use in the communication of financial literacy lessons to the rural communities. If the desire of government, NGOs or any other development actor is to reach a wider audience with minimal costs, then they need not look any further but consider using AMT in the form of live radio broadcasts and audio CDs. Lastly our results affirm that delivering financial literacy information through AMT and organising participants in RLCs can significantly change their knowledge levels for better, however, the kind of change received may not necessarily be reflected in all financial literacy aspects. 


\section{References}

Agarwal, S., Driscoll, J.C., Gabaix, X. and Laibson, D., 2009. The age of reason: Financial decisions over the life cycle and implications for regulation. Brookings Papers on Economic Activity, 2009(2), pp.51117.

ARYA, P., 2018. Financial Literacy and Financial Education in India: An Assessment. CASIRJ. Vol 9 Issue 3.

Atkinson, A. and Messy, F.A., 2011. Assessing financial literacy in 12 countries: an OECD/INFE international pilot exercise. Journal of Pension Economics \& Finance, 10(4), pp.657-665.

Banda, F., 2007. Radio listening clubs in Malawi and Zambia: Towards a participatory model of broadcasting. Communicare: Journal for Communication Sciences in Southern Africa, 26(1), pp.130148.

Bansal, S., 2014. Perspective of technology in achieving financial inclusion in rural India. Procedia Economics and Finance, 11, pp.472-480.

Bruhn, M., Ibarra, G.L. and McKenzie, D., 2013. Why is voluntary financial education so unpopular? Experimental evidence from Mexico. The World Bank.

Cackley, A.P., 2010. Consumer Finance: Factors Affecting the Financial Literacy of Individuals with Limited English Proficiency. Report to Congressional Committees. GAO-10-518. US Government Accountability Office.

Chen, H. and Volpe, R.P., 2002. Gender differences in personal financial literacy among college students. Financial services review, 11(3), pp.289-307.

Chester, G. and Neelameghan, A., 2006. Information professional: Knowledge and skills development for serving marginalized and rural communities. Webology, 3(3).

de Bassa Scheresberg, C., 2013. Financial literacy and financial behavior among young adults: Evidence and implications. Numeracy, 6(2), p.5.

Delavande, A., Rohwedder, S. and Willis, R., 2008. Preparation for retirement, financial knowledge and cognitive resources. MRRC Working Paper Series 190.

Falahati, L. and Paim, L.H., 2011. Gender differences in financial literacy among college students. Journal of American Science, 7(6), pp.1180-1183.

Fao Dimitra Project Report, 2011. Community listeners' Clubs: Stepping stones for action in rural areas, Goma DRC.

Finke, M.S., Howe, J.S. and Huston, S.J., 2016. Old age and the decline in financial literacy. Management Science, 63(1), pp.213-230.

Fletschner, D. and Kenney, L., 2014. Rural women's access to financial services: credit, savings, and insurance. In Gender in agriculture (pp. 187-208). Springer, Dordrecht. 
Fletschner, D., Guirkinger, C. and Boucher, S., 2010. Risk, credit constraints and financial efficiency in Peruvian agriculture. The Journal of Development Studies, 46(6), pp.981-1002.

Gale, W.G. and Levine, R., 2010. Financial literacy: What works? How could it be more effective? How Could it be More Effective.

Hanemann, U. and Scarpino, C., 2016. Harnessing the potential of ICTs: Literacy and numeracy programmes using radio, TV, mobile phones, tablets and computers. UNESCO Institute for Lifelong Learning.

Hibbard, J.H., Slovic, P., Peters, E., Finucane, M.L. and Tusler, M., 2001. Is the informed-choice policy approach appropriate for Medicare beneficiaries? Health Affairs, 20(3), pp.199-203.

Hilgert, M.A., Hogarth, J.M. and Beverly, S.G., 2003. Household financial management: The connection between knowledge and behavior. Fed. Res. Bull., 89, p.309.

Hogarth JM., 2006. Financial education and economic development. InG8 International Conference on Improving Financial Literacy

Kamba, M.A., 2009, October. Access to information: The dilemma for rural community development in Africa. Georgia Institute of Technology.

Korniotis, G.M. and Kumar, A., 2011. Do older investors make better investment decisions? The Review of Economics and Statistics, 93(1), pp.244-265.

Literacy, O.M.F., 2013. Financial literacy and inclusion: Results of OECD/INFE survey across countries and by gender. Financial Literacy \& Education, Russia, jun.

Lusardi, A. and Mitchell, O.S., 2008. Planning and financial literacy: How do women fare? American Economic Review, 98(2), pp.413-17.

Lusardi, A. and Mitchell, O.S., 2009. How Ordinary Consumers Make Complex Economic Decisions: Financial Literacy and Retirement Readiness." NBER Working Paper 15350. In Financial Literacy and Planning: Implications for Retirement Wellbeing," In Financial Literacy: Implications for Retirement Security and the Financial Marketplace. Eds A Lusardi.

Lusardi, A. and Mitchell, O.S., 2014. The economic importance of financial literacy: Theory and evidence. Journal of economic literature, 52(1), pp.5-44.

Lusardi, A. and Mitchelli, O.S., 2007. Financial literacy and retirement preparedness: Evidence and implications for financial education. Business economics, 42(1), pp.35-44.

Lusardi, A., 2003. Planning and saving for retirement (p. 2). Working paper. Dartmouth College.

Lusardi, A., 2008. Household saving behavior: The role of financial literacy, information, and financial education programs (No. w13824). National Bureau of Economic Research. 
Lusardi, A., 2008. Household saving behavior: The role of financial literacy, information, and financial education programs (No. w13824). National Bureau of Economic Research.

Lusardi, A., Michaud, P.C. and Mitchell, O.S., 2011. Optimal financial literacy and saving for retirement.

Lusardi, A., Michaud, P.C. and Mitchell, O.S., 2017. Optimal financial knowledge and wealth inequality. Journal of Political Economy, 125(2), pp.431-477.

Mabula, J.B. and Ping, H.D., 2018. Use of Technology and Financial Literacy on SMEs Practices and Performance in Developing Economies. INTERNATIONAL JOURNAL OF ADVANCED COMPUTER SCIENCE AND APPLICATIONS, 9(6), pp.74-82.

Manda, L.Z., 2015. What Makes Radio Listening Clubs as a Participatory Communication for Development Platform Work? A Case Study of Monkey Bay, Malawi. Online Journal of Communication and Media Technologies, 5(4), p.204.

Mchakulu, J.E.J., 2007. Youth participation in radio listening clubs in Malawi. Journal of Southern African Studies, 33(2), pp.251-265.

Mhagamaa, P., 2015. Transforming the Lives of Ordinary People in Malawi Through Radio Listening Clubs. Sociology, 5(11), pp.843-853.

Monyozo, L., 2008. Communicating with Radio: What do We Know? Findings from selected rural radio effectiveness evaluations. African Farm Radio Research Initiative (AFRRI), Farm Radio International, Ottawa, Canada, p.9.

Monticone, C., 2010. How much does wealth matter in the acquisition of financial literacy? Journal of Consumer Affairs, 44(2), pp.403-422.

Mundy, S. and Masok, C., 2011. Towards an effective framework for financial literacy and financial consumer protection in Uganda. Bank of Uganda Paper, 5, pp.1-76.

Nyirenda, D., Makawa, T.C., Chapita, G., Mdalla, C., Nkolokosa, M., O'byrne, T., Heyderman, R. and Desmond, N., 2018. Public engagement in Malawi through a health-talk radio programme 'Umoyo nkukambirana': A mixed-methods evaluation. Public Understanding of Science, 27(2), pp.229-242.

Primo, N. and Khan, A.W., 2003. Gender issues in the information society (p. 24). Paris: UNESCO.

Rodriguez, C., Sánchez, F. and Zamora, S., 2016. On the radio: Effectiveness of the Viva Seguro financial education program. Documento CEDE, (2014-19).

Rogers, E.M., Braun, J.R. and Vermilion, M.A., 1977. Radio forums: a strategy for rural development.

Schwella, E. and Van Nieuwenhuyzen, B.J., 2014. Measuring financial literacy: Developing and testing a measurement instrument with a selected group of South African military officers. Africa Education Review, 11(3), pp.365-385. 
Spader, J., Ratcliffe, J., Montoya, J. and Skillern, P., 2009. The bold and the bankable: How the Nuestro Barrio telenovela reaches Latino immigrants with financial education. Journal of Consumer Affairs, 43(1), pp.56-79.

Toussaint-Comeau, M. and Rhine, S.L.W., 2000. Delivery of Financial Literacy Programs. Federal Reserve Bank of Chicago, Consumer and Community Affairs, Policy Study 2000-7.

Van Rooij, M., Lusardi, A. and Alessie, R., 2011. Financial literacy and stock market participation. Journal of Financial Economics, 101(2), pp.449-472.

Vitt, L.A., Reichbach, G., Kent, J.L. and Siegenthaler, J., 2005. Goodbye to complacency: Financial literacy education in the United States 2000-2005. Retrieved February 22, p.2007.

Warnock, K., 2001. Development Through Radio (DTR) Radio Listening Clubs, Zambia: Impact Evaluation Report. 